\title{
Acompanhamento dos Estudantes pela Comissão Coordenadora do Curso de Enfermagem da Universidade de São Paulo
}

\author{
Valéria Marli Leonello, Célia Maria Sivalli Campos, Cecília Helena de Siqueira Sigaud*, Aurea \\ Tamami Minagawa Toriyama, Paula Cristina Nogueira \\ Escola de Enfermagem da Universidade de São Paulo
}

* Autora para correspondência: csigaud@usp.br

\section{RESUMO}

O objetivo deste relato é descrever a atividade de acompanhamento pedagógico e apoio aos estudantes, realizada pela Comissão Coordenadora do Curso (CoC) do bacharelado em Enfermagem da Escola de Enfermagem da USP (EEUSP), formada por quatro professoras que se colocam como tutoras de referência para cada uma das quatro turmas de graduandos. Esse processo tem se mostrado como um instrumento que nos desvela limites e potencialidades do currículo, desencadeando processos de enfrentamento institucional, como aprimoramento do curso, realização de atividades voltadas à formação docente, promoção de mostra cultural e exibição de filmes com debate. Tais atividades vêm contribuindo para a qualificação da formação de enfermeiros.

Palavras-Chave: Educação em Enfermagem; Educação Superior; Estudantes de Enfermagem.

\begin{abstract}
The aim of this report is to describe the pedagogical support to nursing undergraduate students, carried out by the Coordinating Committee of the Course $(\mathrm{CoC})$ of bachelor in Nursing of the Escola de Enfermagem da Universidade de São Paulo (EEUSP), integrated by four teachers, who develop tutoring activities. This process has permitted to reveal the curriculum limits and potentialities, and triggered institutional actions to improve the course, such as teacher training, cultural activities, movies exhibitions and debates. Such activities have improved the nursing undergraduate students qualification.
\end{abstract}

Keywords: Education; Nursing; Higher Education; Students.

\section{Introdução}

Estudantes das diversas turmas têm expressado sinais de ansiedade e sintomas de desgaste, consequência das pressões a que os jovens têm sido submetidos, tanto aquelas internas à universidade e às condições para frequentar o curso - múltiplas atividades, competição por notas, deslocamento na cidade de São Paulo - quanto aquelas externas à universidade - cobrança relativa à profissão, que deve dar prazer e sucesso financeiro, ser o melhor, não perder as oportunidades, entre outras pressões e desconfortos, os quais Birman (2007) descreveu como os mal-estares contemporâneos.

Estudantes de enfermagem estão mais sujeitos a apresentar manifestações psicológicas e fisiológicas de estresse, se comparados com estudantes de outras áreas (BENAVENTE \& COSTA, 2011). Então, compreender a dinâmica de funcionamento do curso e as situações que podem interferir no percurso acadêmico tem sido um desafio para os estudantes de enfermagem.

Em concordância com o regimento ${ }^{1}$, cabe às Comissões Coordenadoras de Curso (CoG) da EEUSP monitorarem o percurso de formação dos graduandos, proporem possibilidades de enfrentamento de desgastes e realizarem ações voltadas ao desenvolvimento do curso. A GoC bacharelado é composta por quatro docentes representantes dos departamentos da EEUSP, um docente representante de uma unidade da USP que colabora com o curso e quatro graduandos representantes de cada uma das turmas. Essa CoC vem realizando o 
acompanhamento e oferecendo apoio aos estudantes desde 2014, por meio de tutorias acadêmicas feitas periodicamente pelas professoras em parceria com os discentes que compõem essa comissão.

\section{O Acompanhamento dos Estudantes}

As atividades desenvolvidas estão identificadas na Figura 1.

A operacionalização dessas atividades é feita de forma individual e em grupo.

Individualmente, os estudantes procuram as tutoras para orientações acadêmicas, a exemplo da elaboração de planos de estudo e do apoio no enfrentamento de dificuldades, bem como para abordagem de questões pessoais que refletem em sua trajetória no curso.

Em grupo, as tutoras e representantes discentes fazem abordagens nas salas de aula com o objetivo de ouvir e orientar a turma com relação às dificuldades, dúvidas e sugestões acadêmicas.

No que diz respeito ao primeiro ano, os ingressantes trazem dúvidas e dificuldades relacionadas ao percurso acadêmico e à profissão, além de ansiedades decorrentes do ingresso no ensino universitário.

No segundo e terceiro anos, os estudantes iniciam a prática assistencial de enfermagem, o que gera insegurança. Além disso, inserem-se em atividades extracurriculares, como iniciação científica, ligas acadêmicas e outras atividades extramuros e de serviços à comunidade. Percebe-se que os estudantes demonstram ansiedade e cansaço com o acúmulo de tarefas, fazendo-se necessário apoio para se organizarem de forma a evitar sobrecarga e sentimento de insuficiência.

O quarto e último ano produz ansiedade nos estudantes, relacionada a expectativas e dúvidas quanto ao ingresso no mundo do trabalho. Essa escuta originou a realização de trabalho em grupo com a finalidade de apoiá-los.

A CoG bacharelado realiza também reuniões sistemáticas e anuais com coordenadores das disciplinas curriculares, com o intuito de promover troca de experiências de ensino e fortalecer a articulação entre elas.
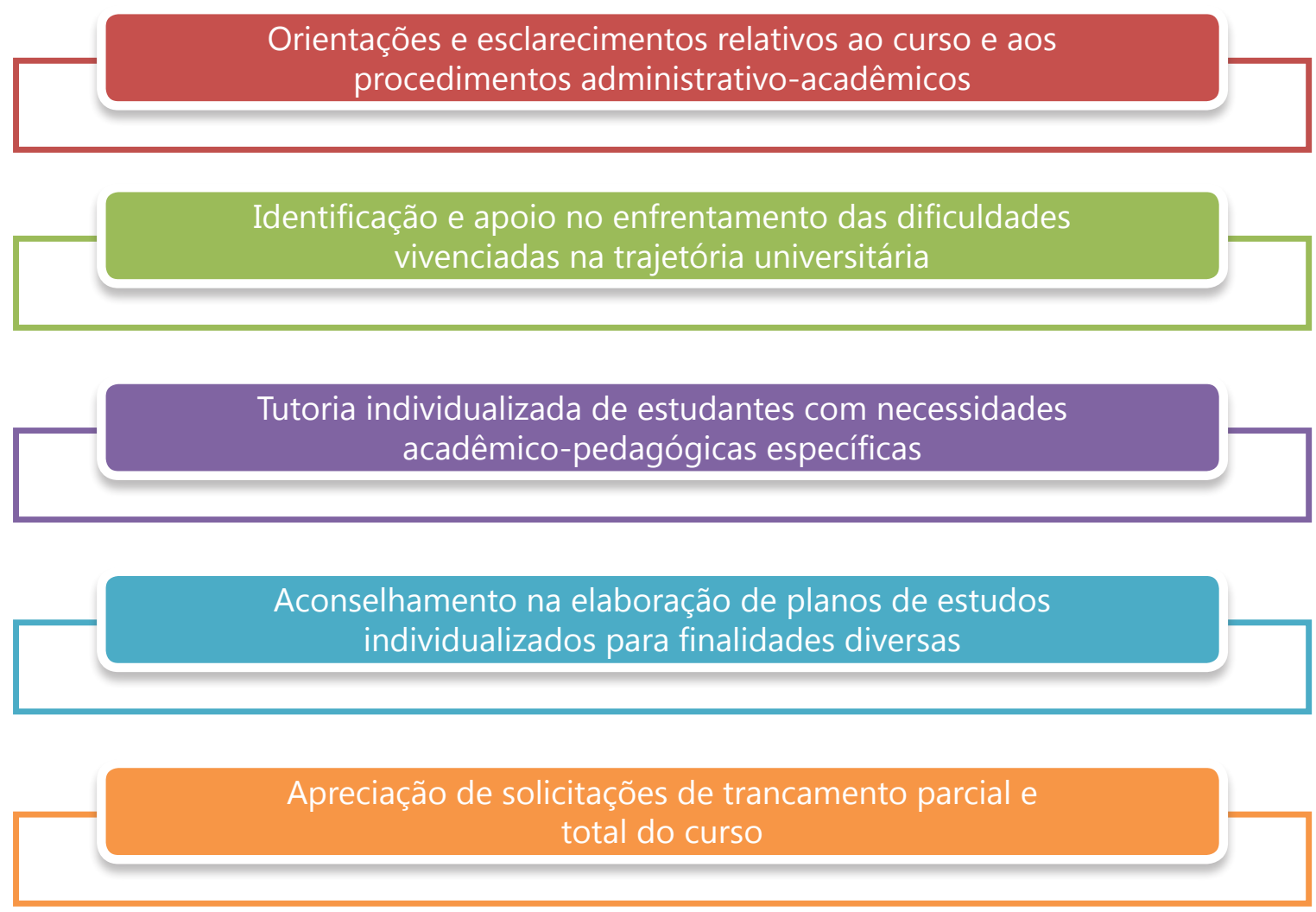

Figura 1 - Atividades desenvolvidas pelas professoras da CoC e representantes de turma para acompanhamento dos estudantes. 


\section{O Impacto do Acompanhamento}

Como resultados preliminares desse acompanhamento, destacam-se: o fortalecimento do vínculo entre as professoras da CoC e estudantes; a apropriação de conhecimentos relacionados aos procedimentos acadêmicos e à proposta curricular pelos discentes; e a identificação de novas demandas para o aperfeiçoamento do curso e da gestão do curso, por discentes e docentes.

Essa tutoria possibilitou também desvelar desgastes vivenciados no processo de ensino-aprendizagem e desencadeou processos de enfrentamento institucional. Um deles refere-se ao aprimoramento da proposta curricular, com destaque para: a flexibilização da política de pré-requisitos de disciplinas, a fim de possibilitar a progressão dos estudantes no curso; o reconhecimento da autonomia e a ampliação da liberdade estudantil para a escolha das atividades acadêmicas complementares; e o empenho da comissão para preservar espaços livres na grade curricular e estimular os professores à promoção de períodos de estudo não presencial, além da manutenção das atividades curriculares dentro dos períodos reservados às disciplinas.

Promoveram-se também atividades institucionais dirigidas à formação do corpo docente, como palestras, mesas-redondas e workshops, com temática de ética e metodologias dialógicas no ensino de enfermagem, diretrizes curriculares nacionais para o curso de enfermagem, entre outras.

Outro produto do trabalho de tutoria estudantil foi a realização da mostra cultural da EEUSP, organizada anualmente em conjunto com estudantes, como espaço para expressão artística da comunidade da EEUSP, exibição de filmes com debate e discussão sobre o trote no ingresso à universidade.

A procura crescente pelos docentes da CoC bacharelado é um indicador do reconhecimento desse acompanhamento como recurso para enfrentamento de dificuldades dos estudantes.

Embora sejam reconhecidos avanços no acompanhamento do processo de formação dos futuros enfermeiros, há desafios a serem enfrentados, como a dificuldade de envolvimento de um número maior de docentes no ensino de graduação, em razão da redução dos quadros da universidade.

\section{Considerações Finais}

$\mathrm{O}$ acompanhamento realizado pelos membros da CoC potencializa e qualifica a formação estudantil universitária, possibilitando o diagnóstico mais preciso do currículo, constituindo-se importante ferramenta para a elaboração de propostas de ajustes e de aprimoramento do curso.

\section{Nota}

1 Regimento das Comissões Coordenadoras de Curso, aprovado pela Congregação da EEUSP em 14 de novembro de 2012.

\section{Referências Bibliográficas}

ALMEIDA Maria Isabel de \& PIMENTA Selma Garrido. "Pedagogia Universitária: Valorizando o Ensino e a Docência na Universidade". Revista Portuguesa de Educaşão, vol. 27, n. 2, 2014, pp. 7-31.

BENAVENTE Sonia Betzabeth Ticona \& COSTA Ana Lucia Siqueira. "Respostas Fisiológicas e Emocionais ao Estresse em Estudantes de Enfermagem: Revisão Integrativa da Literatura Científica". Acta Paulista de Enfermagem, vol. 24, n. 4, 2011, pp. 571-576.

BIRMAN Joel. "Laços e Desenlaces na Contemporaneidade". Jornal de Psicanálise, vol. 40, n, 42, 2007, pp. 47-62.

Publicado em 04/07/2018. 